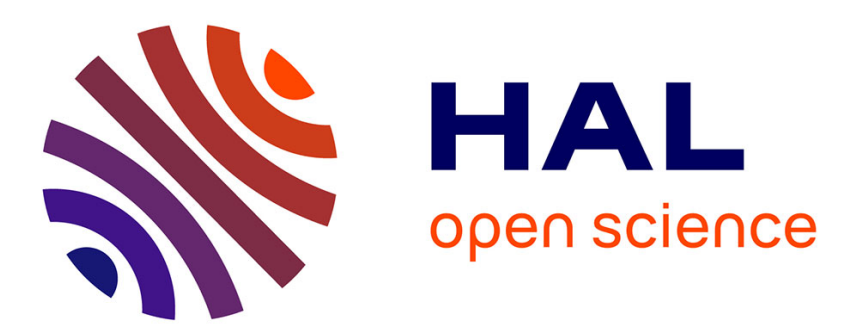

\title{
Stability of Ultrathin Ceria Films on Pt(111) Exposed to Air and Treated in Redox Cycles
}

\author{
Gabriele Gasperi, Paola Luches, Clemens Barth
}

\section{To cite this version:}

Gabriele Gasperi, Paola Luches, Clemens Barth. Stability of Ultrathin Ceria Films on Pt(111) Exposed to Air and Treated in Redox Cycles. Journal of Physical Chemistry C, 2018, 122 (45), pp.25954-25963. 10.1021/acs.jpcc.8b07231 . hal-01914683

\section{HAL Id: hal-01914683 \\ https://hal.science/hal-01914683}

Submitted on 7 Nov 2018

HAL is a multi-disciplinary open access archive for the deposit and dissemination of scientific research documents, whether they are published or not. The documents may come from teaching and research institutions in France or abroad, or from public or private research centers.
L'archive ouverte pluridisciplinaire HAL, est destinée au dépôt et à la diffusion de documents scientifiques de niveau recherche, publiés ou non, émanant des établissements d'enseignement et de recherche français ou étrangers, des laboratoires publics ou privés. 


\title{
Stability of Ultra-Thin Ceria Films on $\mathrm{Pt}(111)$ Exposed to Air and Treated in Redox Cycles
}

\author{
G. Gasperi, ${ }^{\dagger}$ P. Luches, ${ }^{\dagger}$ and C. Barth ${ }^{*, \dagger}$ \\ Istituto Nanoscienze, Consiglio Nazionale delle Ricerche, Via G. Campi 213/a, Modena \\ 41125, Italy, and Aix-Marseille Université, CNRS, CINaM UMR 7325, 13288 Marseille, \\ France
}

E-mail: barth@cinam.univ-mrs.fr

${ }^{*}$ To whom correspondence should be addressed

${ }^{\dagger}$ Istituto Nanoscienze, Consiglio Nazionale delle Ricerche, Via G. Campi 213/a, Modena 41125, Italy

${ }^{\ddagger}$ Aix-Marseille Université, CNRS, CINaM UMR 7325, 13288 Marseille, France 


\begin{abstract}
The stability of cerium oxide (ceria) is a major topic in the field of heterogeneous catalysis. When exposed to a reactive environment or treated in a redox step, ceria is prone to changes of its surface morphology, atomic structure and composition, with a strong impact onto its catalytic properties. Here, we investigate the stability of $\mathrm{Pt}(111)$-supported ultra-thin ceria films upon air exposure and during redox cycles under ultra-high vacuum (UHV) conditions. Scanning probe microscopy, X-ray photoemission spectroscopy and low energy electron diffraction show that upon air-exposure a clean ceria film surface gets contaminated by hydroxyls and carbon-containing species whereas a following annealing in molecular oxygen at around $650{ }^{\circ} \mathrm{C}$ removes such contaminants and allows to restore the original surface morphology and structure. When clean films are oxidized in a background oxygen pressure (reduced in UHV) at $\sim 650$ ${ }^{\circ} \mathrm{C}$, the film coverage increases (decreases). The decrease of the film coverage upon reduction is probably due to a release of cerium atoms, which form an alloy with the platinum substrate that acts as a reservoir for cerium atoms. Due to the alloying, the surface work function $(\mathrm{WF})$ of $\mathrm{Pt}(111)$ decreases by $\triangle \phi_{\mathrm{CeP} t_{5} / \mathrm{Pt}(111)-\mathrm{Pt}} \approx-0.20 \pm 0.05$ $\mathrm{eV}$, as observed by Kelvin probe force microscopy. Upon oxidation, the released cerium is used to form new ceria. With respect to WF changes of the $\operatorname{Pt}(111)$ surface by the ceria film, a decrease is found for the oxidized film $\left(\triangle \phi_{\mathrm{CeO} 2 / \mathrm{Pt}-\mathrm{Pt}} \approx-0.55 \pm 0.05 \mathrm{eV}\right)$ as well as for the reduced film $\left(\triangle \phi_{\text {rCeria } / \mathrm{Pt}-\mathrm{Pt}} \approx-0.60 \pm 0.05 \mathrm{eV}\right)$.
\end{abstract}




\section{INTRODUCTION}

Cerium oxide (ceria) is a most important material in heterogeneous catalysis ${ }^{1,2}$ due to its high oxygen storage capacity (OSC), which is based on the oxidation and reduction of cerium ions and the accompanied filling and creation of oxygen vacancies, respectively ${ }^{3}$. For instance, ceria is used in the water-gas-shift reaction ${ }^{4,5}$, for the oxidation of hydrocarbons ${ }^{1,5}$ and for fuel cells ${ }^{6-8}$, with the most prominent application being the three-way-catalyst ${ }^{2,9}$.

To understand fundamental mechanisims involved in redox processes and related surface chemistry ${ }^{3,10}$, well-defined ceria model surfaces, in particular in the form of thick ${ }^{11}$ and ultra-thin films ${ }^{12-15}$, have been studied in heterogeneous model catalysis. Since ceria is very reactive to many different types of molecular species ${ }^{14}$, model surfaces are mostly prepared in ultra-high vacuum (UHV) where utmost surface cleanness can be guaranteed. An advantage of studying ceria in the form of films is that the entire palette of surface science techniques can be used, such as X-ray photoemission spectroscopy (XPS), low energy electron diffraction (LEED) ${ }^{13-15}$, scanning tunneling microscopy (STM) ${ }^{12-16}$ and noncontact atomic force microscopy (nc-AFM) ${ }^{11,17}$ to name a few.

A very important aspect in the research on ceria films concerns its morphological and atomic structure stability upon exposure to a gaseous environment and upon thermal treatments during a redox cycle. For instance, when ceria is reduced or oxidized, structural properties like the surface morphology and atomic structure change ${ }^{18-21}$. Whereas such changes only depend on the interplay between bulk ceria and its surface in the case of bulk-like thick films ${ }^{20,22,23}$, the case of ultra-thin films is different due to the presence of the metal surface underneath: for instance, 2 and 10 monolayer ultra-thin ceria films supported on a $\operatorname{Pt}(111)$ surface show a different reducibility due to a reduced dimensionality and the influence of the substrate ${ }^{24}$. Moreover, such films release cerium atoms during vacuum reduction at high temperatures and an alloy is formed between cerium and platinum ${ }^{25}$. Vice-versa, a ceria film is formed when the alloy is thermally annealed in oxygen ${ }^{26,27}$. The same applies also for gold surfaces ${ }^{28}$, while if the metal support does not form an alloy with cerium, the released 
cerium forms small nanoparticles ${ }^{29}$. Whereas all these and many other structural changes have been studied only in a single step of a redox process there are only a few works, which focus on changes that appear within, at least, one complete redox cycle ${ }^{19}$.

Important also with respect to ceria's stability are structural and chemical changes that appear when ceria is exposed to the ambient air. This is not only important in the real catalysis world but it is of pratical interest in surface science where ceria samples are transferred between UHV systems. When exposed to the ambient air, ceria gets contaminated in particular by surface hydroxyl groups and carbon containing species with the result that an irregular structure on the otherwise atomically flat terraces is created ${ }^{23}$, like on air-cleaved bulk $\mathrm{MgO}(001)^{30}$ and $\mathrm{CaF}_{2}(111)^{31}$. Recently, it has been shown that on air-exposed thick ceria films an annealing in a controlled environment of molecular oxygen $\left(\sim 10^{-6}\right.$ mbar $)$ at around $650{ }^{\circ} \mathrm{C}$ removes almost all contaminants leaving behind a well-defined and pristine surface of $\mathrm{CeO}_{2}(111)^{23}$.

In the work here we investigate ceria's stability in the ambient air and upon thermal treatments in a redox cycle under UHV conditions. We first comment that an air-exposed ceria surface can be accurately cleaned merely by oxygen annealing even if ceria is in the extreme shape of an ultra-thin film. We show that this is indeed possible by considering an ultra-thin ceria film on $\mathrm{Pt}(111)$ - a standard film system that has been carefully studied by LEED, XPS, resonant inelastic X-ray scattering and STM before ${ }^{19,24-27,32-36}$. For analyzing the composition, oxidation state and surface contaminants we used XPS, whereas the long-order crystallinity and the morphology of the films were analyzed by LEED and STM/nc-AFM, respectively. In a second part, we consider the same clean film and comment structural changes in the film morphology that appear within two redox cycles. Kelvin probe force microscopy (KPFM) was additionally used to obtain information on the local surface work function (WF) at the nanometer scale ${ }^{37}$. In particular KPFM proved to be important to reveal and understand phenomena of surface alloying within a redox cycle. In general, WF related phenomena on metal supported oxide films are of high interest in model catalysis 
because such films have the strong tendency to change the metal's WF with direct consequences on adsorption properties and reactivity ${ }^{38,39}$. So far, no WF study at the nanometer scale has been accomplished on ceria ultra-thin films on any type of metal surface.

\section{METHODS}

The film preparation was done at the CNR NANO laboratory in Modena (Italy). A Pt(111) substrate was cleaned by repeated cycles of sputtering and high-temperature annealing at 770 ${ }^{\circ} \mathrm{C}$. A ceria ultra-thin film was grown by reactive evaporation of cerium in molecular oxygen $\left(1 \times 10^{-7} \mathrm{mbar}\right)$ onto the $\mathrm{Pt}(111)$ substrate kept at room temperature. The cerium oxide film was post-annealed at $770{ }^{\circ} \mathrm{C}$ in $10^{-7} \mathrm{mbar} \mathrm{O}_{2}$ for $15 \mathrm{~min}$. The nominal thickness was about 2.3 monolayers (ML). One ML is defined as the thickness of the repeating unit along the [111] direction, namely an O-Ce-O trilayer with a height of $h_{\mathrm{TL}}=a_{\mathrm{CeO} 2} / \sqrt{3} \approx 3.12 \pm 0.01$

$\AA$ (for the lattice constant $a_{\mathrm{CeO} 2}$ of $\mathrm{CeO}_{2}$ see Table $\mathrm{S} 3$ in the Supporting Information). After the growth, the sample was carried in a glass vacuum desiccator filled with pure nitrogen at ambient pressure to the CINaM laboratory in Marseille (France). The sample was exposed to the ambient air for a few minutes during the transfer of the sample from the UHV system in Modena to the desiccator. A comparable air exposure took place in Marseille, and again two times when the sample was transported back to Modena for XPS measurements.

STM and LEED experiments were conducted at both laboratories in UHV and at room temperature, with the instruments being almost identical. XPS was done only in Modena whereas nc-AFM and KPFM were only done in Marseille. KPFM was used in the frequency modulation mode and applied during the constant frequency nc-AFM imaging mode (frequency modulated nc-AFM) ${ }^{37}$. During the scanning of the surface, a work function image is obtained simultaneously with the topography nc-AFM image. The contrast of a WF image is directly related to WF differences on the surface. A bright contrast in WF images corresponds to a high WF and vice-versa. XPS was performed using $\mathrm{Al} \mathrm{K}_{\alpha}$ photons, and 
photoelectrons were detected at an emission angle of $65^{\circ}$ from the sample normal to increase the surface sensitivity.

Further details about the sample preparation, the SPM, XPS and LEED techniques and analysis, as well as details about the lattice constant of $\mathrm{Pt}$ and $\mathrm{CeO}_{2}$ and the absolute WF of the Pt(111) surface can be found in the Supporting Information.

\section{RESULTS}

Stability after air exposure. Directly after the preparation of the 2.3 ML ultra-thin ceria film, we conducted LEED measurements to check the long-range crystallinity of the film. STM was additionally used to analyze the surface morphology at the nanometer scale. Figure 1a shows typical properties that can be generally found on such an as-prepared ceria film $^{35,36}$ : the LEED image acquired at $80 \mathrm{eV}$ shows six inner, hexagonally arranged spots, which can be related to the ceria film being in its oxidized form of $\mathrm{CeO}_{2}(111)$, with a negligible $\mathrm{Ce}^{3+}$ concentration $\left(c_{\mathrm{Ce} 3+}=1 \%\right)$ as verified by XPS (see Figure S1 in the Supporting Information). While the precision of the $\mathrm{Ce}^{3+}$ concentration obtained by the analysis of the Ce3d XPS spectra is quite high, within $\pm 1-2 \%$, its accuracy is certainly worse, \pm 5 \%. The outer six hexagonally arranged spots belong to the $\operatorname{Pt}(111)$ substrate, which is partially exposed as a clean surface (see below). The ratio of the reciprocal lattice vectors of $\operatorname{Pt}(111)$ and $\mathrm{CeO}_{2}(111)$ is around $r=1.37 \pm 0.01$, which is a typical value for this thin film system $^{27,35,36}$. Although the value is compatible with the expected ratio of the Pt and ceria bulk lattices $\left(r_{\text {ideal }}=1.380 \pm 0.005\right.$, for Pt and ceria lattice values see Table S2 and S3 in the Supporting Information), the slightly smaller value is consistent with previous observations of a possible strain-induced lattice contraction of ceria ultrathin films on $\operatorname{Pt}(111)^{25,27,35}$ (see further below). With the lattice constant of $a_{\mathrm{Pt} \text {,lit }}=3.92 \pm 0.01 \AA$ for Pt (see Table S2 in the Supporting Information) and the resulting $e_{\mathrm{CeO} 2(111)}=a_{\mathrm{Pt}, \mathrm{lit}} / \sqrt{2}=2.77 \pm 0.01 \AA$ next-neighbour Pt-Pt distance, a value of $e_{\mathrm{CeO}(111)}=3.80 \pm 0.03 \AA$ is obtained for the 

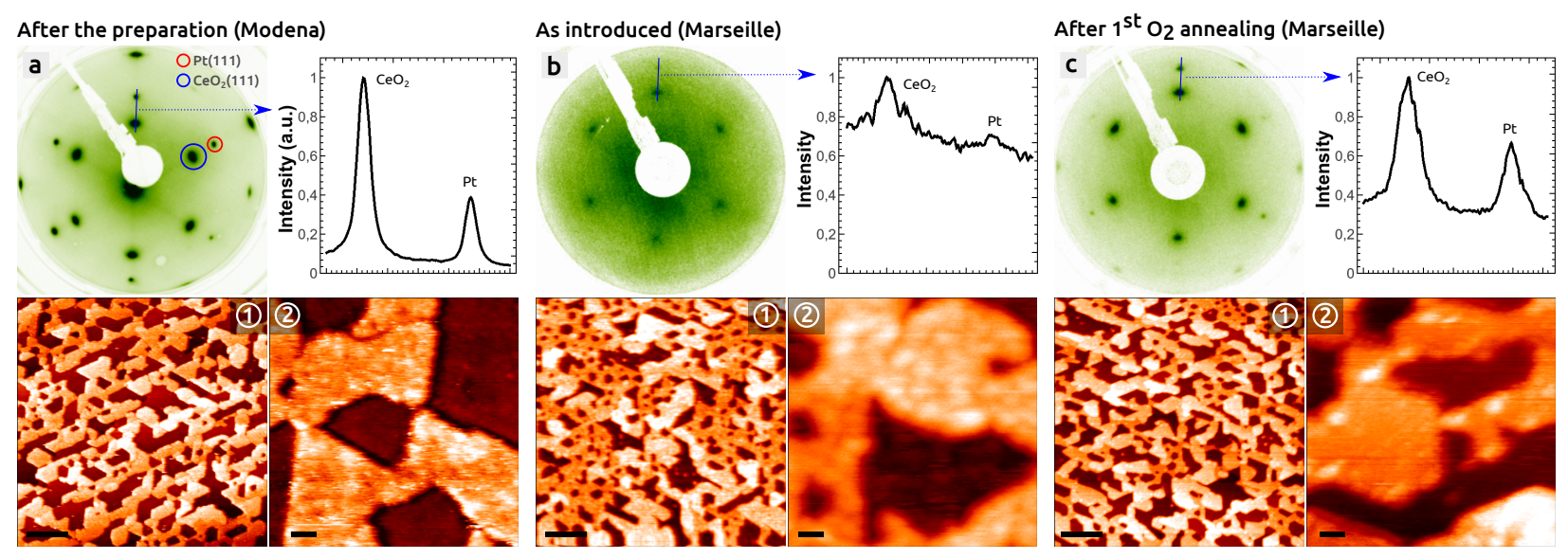

Figure 1: The 2.3 ML ultra-thin ceria film on $\mathrm{Pt}(111)$ after its preparation (a), after exposure to air for $\sim 15$ minutes (b) and after its first oxidation at $670{ }^{\circ} \mathrm{C}$ in $5.0 \times 10^{-7} \mathrm{mbar}_{2}$ for 15 minutes (c). For each stage, a LEED image obtained at $80 \mathrm{eV}$ (blue) with a corresponding profile, as well as one SPM topography image on a large (1) and small scale (2) are shown. STM parameters: (a) $U_{\text {Bias }}=1.0 \mathrm{~V}, I=0.037 \mathrm{nA}(1,2), v=0.5$ (1) and $1.0 \mathrm{~Hz}(2)$, nc-AFM parameters: (b) $\triangle f=-11.7$ (1) and $-18.1 \mathrm{~Hz}(2)$, (c) $\triangle f=-11.1 \mathrm{~Hz}$, all nc-AFM: $v=0.5$ $\mathrm{Hz}, f_{0}=300.0 \mathrm{kHz}$, all: scale bars: $50 \mathrm{~nm}(1)$ and $5 \mathrm{~nm}(2)$.

surface lattice parameter of $\mathrm{CeO}_{2}$ film, which is in agreement with the value found in Refs. 35 and 36. Overall, the LEED data shows that the $\mathrm{CeO}_{2}(111)$ film is well ordered and has a high crystallinity.

In the real space, on a scale of a few hunderds of nanometers (Figure 1a, image 1), the film exhibits the typical island-network structure with islands as high as 2 to 3 ML (0.6 to $0.9 \mathrm{~nm}$ ) and with the $\mathrm{Pt}(111)$ substrate being partially uncovered ${ }^{35,36}$. On a scale of a few tens of nanometers (Figure 1a, image 2), the Pt(111) support and the ceria islands are almost atomically flat.

Figure $1 \mathrm{~b}$ shows same type of measurements after the transfer of the ceria sample between the two laboratories accompanied by short air-exposures. The as-introduced ceria film shows the ceria-related peaks and a rather high background intensity in the rest of the image. The background intensity is due to electrons inelastically scattered by surface defects originating from the air (see below). The six peaks from the $\mathrm{Pt}(111)$ support, which were very sharp 
after the growth (see profile in Figure 1a), all vanished despite one spot, which can be seen in the LEED profile shown in Figure 1b. The ratio of the reciprocal lattice vectors of $\mathrm{Pt}(111)$ and $\mathrm{CeO}_{2}(111)$ has slightly changed $(r=1.34 \pm 0.03)$, pointing again to the above mentioned contraction of the ceria lattice. In contrast to LEED, nc-AFM shows a morphology that seems to be quite similar to the one obtained by STM after the growth: it shows the same network character of the film on a large scale (Figure 1b, image 1). Merely a granular structure on the film and on the Pt(111) terraces can be observed (Figure 1b, image 2), which resembles much the granular structures observed on thick ceria films ${ }^{23}$, air-cleaved $\mathrm{MgO}(001)^{30}$ and $\mathrm{CaF}_{2}(111)^{31}$. As it will be discussed further below, this granular structure is formed by surface hydroxyls and carbon species.

To clean and completely oxidize the ceria film, we annealed the sample at $670{ }^{\circ} \mathrm{C}$ in $5.0 \times 10^{-7}$ mbar molecular oxygen for 15 minutes (Figure 1c). As shown in the LEED image, all the six hexagonally arranged $\mathrm{CeO}_{2}(111)$ and $\mathrm{Pt}(111)$ peaks recurred (compare profile with the profile in Figure 1a). The ratio of the reciprocal lattice vectors of this oxygen annealed ceria film $(r=1.33 \pm 0.02)$ is comparable to the one of the same sample before the oxygen treatment. The overall long-range crystallinity of the film is very good. Merely the background of the LEEM image in Figure 1c is a bit higher than in Figure 1a, possibly due to the different electron guns used in the two LEED apparatus (see Supporting Information).

No visible modifications in the film morphology at the nanometer scale could be detected (Figure 1c): as in the two stages before, large (image 1) and small-scale nc-AFM images (image 2) show an almost unchanged ceria film on $\mathrm{Pt}(111)$, with a slight improvement of the overall flattness of the film and support.

XPS spectra were acquired (Figure 2) after prolonged air exposure (see above) on the as-introduced film (black spectra), after an annealing at $650{ }^{\circ} \mathrm{C}$ in $1.0 \times 10^{-7}$ mbar molecular oxygen (red spectra) and after a following reduction at $630{ }^{\circ} \mathrm{C}$ in UHV for 60 minutes (blue spectra). To reveal the oxidation state of the ceria film, the Ce3d (a), O1s (b) and C1s (c) spectra were analyzed with respect to surface contaminations. By analyzing survey spectra 
(results not shown), we made sure not to miss any contamination. Furthermore, the Pt4f peaks (not shown) did not exhibit any modification or shoulder, both after air exposure and thermal treatments.

From the Ce3d spectrum, we determined the $\mathrm{Ce}^{3+}$ concentration in the film by fitting the spectra using $\mathrm{Ce}^{3+}$ and $\mathrm{Ce}^{4+}$ related doublets and relating the area of the $\mathrm{Ce}^{3+}$ doublets to the total multiplet area ${ }^{19}$. The as-introduced ceria sample, which was fully oxidized after its preparation, got only slightly reduced in air and had a $19 \%$ concentration of $\mathrm{Ce}^{3+}$ (black spectrum), which decreased to $5 \%$ after the annealing in oxygen (red spectrum). Upon reduction by annealing in UHV (blue spectrum), the $\mathrm{Ce}^{3+}$ concentration increased to $36 \%$, which confirms the efficiency of a reduction by UHV annealing ${ }^{19,23}$. The first two values of the $\mathrm{Ce}^{3+}$ concentration are in good agreement with values obtained on thick ceria films ${ }^{23}$ : a concentration of $15 \%$ and $6 \%$ were determined for an air-exposed thick film and after annealing at $657^{\circ} \mathrm{C}$ in $6 \times 10^{-6}$ mbar molecular oxygen for 2 hours, respectively. The $\mathrm{Ce}^{3+}$ concentration of $36 \%$ after the reduction of the ultra-thin film is different from other values obtained in previous works on $\mathrm{Pt}$ supported cerium oxide films ${ }^{35}$ because the degree of reduction strongly depends on the film thickness and annealing time.

The important question is if surface contaminants are adsorbed on the air exposed ceria film and if these can be removed by oxygen annealing. The O1s spectra in Figure 2b show relevant modifications with the different treatments. The spectra were fitted using three components, peak $1(529.1 \mathrm{eV})$, assigned to oxygen bound to $\mathrm{Ce}^{4+29,40}$, peak $2(530.1 \mathrm{eV})$, assigned to oxygen bound to $\mathrm{Ce}^{3+}{ }^{29,40}$, and peak $3(531.5 \mathrm{eV})$, assigned to hydroxyls and/or $\mathrm{H}_{2} \mathrm{O}$ molecules ${ }^{41,42}$. The peak areas obtained from the fit of the spectra after the different treatments are reported in Table S5 of the Supporting Information. After the annealing of the sample in oxygen, the shoulder (peak 3) disappeared and peak 1 remained almost unchanged, whereas the following reduction by UHV annealing induced an increase of the intensity of peak 2 and a decrease of the intensity of peak 1, as expected considering the increase of $\mathrm{Ce}^{3+}$ concentration form $5 \%$ to $36 \%$ determined from the Ce3d analysis (see Table 

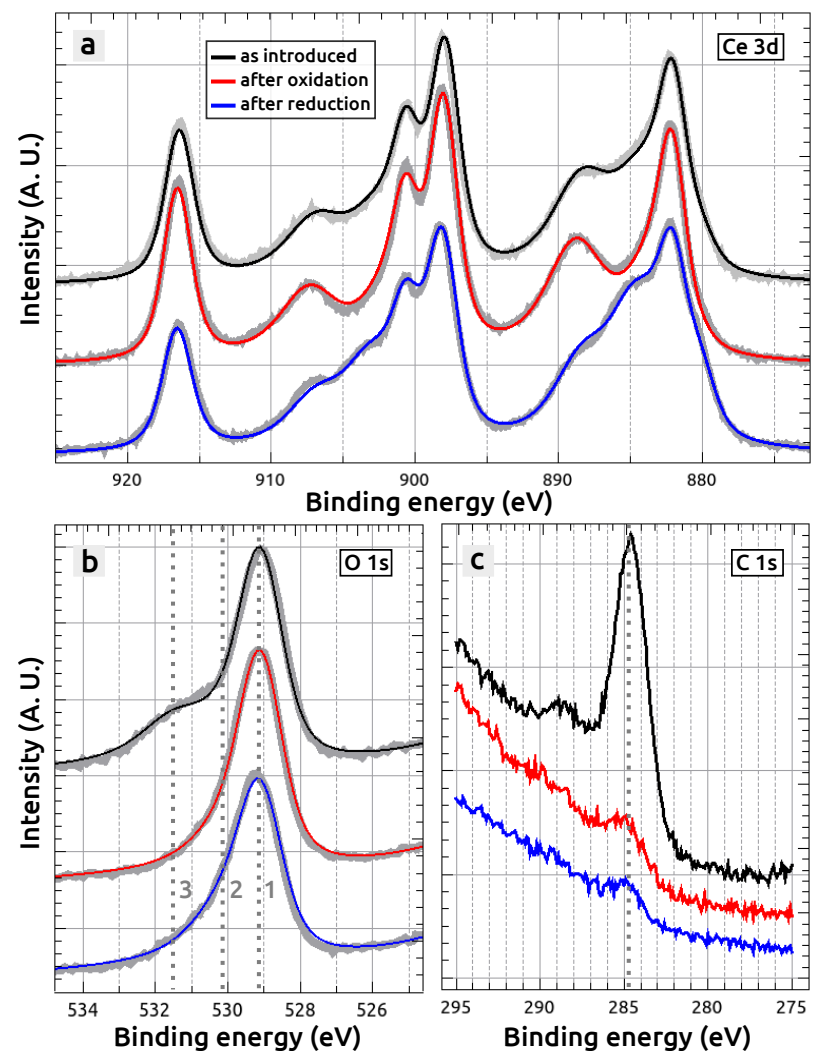

Figure 2: X-ray photoemission Ce3d (a), O1s (b) and C1s spectra (c). The black, red and blue spectra show the film as-introduced into the UHV chamber after air exposure, after an annealing at $650{ }^{\circ} \mathrm{C}$ in $1.0 \times 10^{-7}$ mbar $\mathrm{O}_{2}$ during 15 minutes and after a UHV annealing at $630{ }^{\circ} \mathrm{C}$ during 60 minutes, respectively. The solid lines are fits of the spectra.

$\mathrm{S} 5$ of the Supporting Information). The large C1s peak at $\sim 284.5 \mathrm{eV}$ (Figure 2c) shows that the as-introduced film initially carried some carbon. After the annealing of the sample in oxygen, the peak almost disappeared and remained on the same extremely low level after the following annealing in UHV.

The XPS data clearly show that ultra-thin ceria films are prone to same surface reactions when exposed to the ambient air as thick ceria films ${ }^{23}$. We speculate that during the airexposure, water and carbon containing gas molecules get adsorbed on the film surface, which explains the strong hydroxyl and carbon peaks in the spectra. Alongside, a fully oxidized ceria film does not get much reduced upon air exposure due to the net oxidation effect in the ambient air, as also observed on ceria films on $\operatorname{Si}(111)^{43}$. The oxygen annealing removes the 
hydroyls, presumably by forming water, and the carbon species forming probably CO and $\mathrm{CO}_{2}$. After the oxygen annealing, the ceria film is perfectly clean in its fully oxidized form of $\mathrm{CeO}_{2}(111)$ like thick ceria films ${ }^{23}$. Important to remark is that the film with its long-range crystallinity and the characteristic network morphology remained amazingly stable.

Stability with redox cycles. In our previous work ${ }^{19}$, we qualitatively described changes of the film morphology upon a reduction and oxidation of ceria. Here we present a quantitatve analysis of such morphological changes, with the help of several reduction/oxidation experiments conducted in two complete redox cycles as shown in Figure 3 and summarized in table S1 of the Supporting Information. The first redox cycle started with the oxygen treatment described above, with the image in Figure 3a being the same as image 1 in Figure 1c. We conducted a second oxidation of the film with the same temperature and oxygen pressure (Figure 3b) and subsequently reduced the film by UHV annealing at $639{ }^{\circ} \mathrm{C}$ for 1.5 hours (Figure 3c). To test the stability of the film and detect any changes of the film morphology in dependence on the annealing temperature and time, we conducted a second reduction at a higher temperature of $700{ }^{\circ} \mathrm{C}$ for 1 hour (Figure S2 in the Supporting Information) and a third one at $580{ }^{\circ} \mathrm{C}$ for 8 hours (Figure $3 \mathrm{~d}$ ). The second redox cycle started with an oxydation of the film at $600{ }^{\circ} \mathrm{C}$ for 1 hour (Figure 3e) and finished with a following reduction at $640{ }^{\circ} \mathrm{C}$ for 1.5 hours (Figure $3 f$ ).

After the first oxydation of the first cycle (Figure 3a), the ceria film exhibited islands at least $2 \mathrm{ML}$ high (see Section 4.4 in the Supporting Information), in agreement with our previous observations ${ }^{35}$. Adjacent edges of the islands formed angles of mainly $120^{\circ}$ as we observed before $^{19}$. After the second oxidation (Figure 3b), the characteristic '120 shape' became more pronounced whereas the surface coverage of the ceria film $(\sim 66 \%$ (a) and $\sim 67$ $\%$ (b) did not change significantly considering the experimental error of $6 \%$ (see Section 4.5 in the Supporting Information). Upon reduction (Figure 3c,d), the characteristic $120^{\circ}$ angles almost disappeared but the atomic flatness of the film and the island height did not change. An important observation is that the surface coverage of the film decreased to $\sim 59 \%$ after 


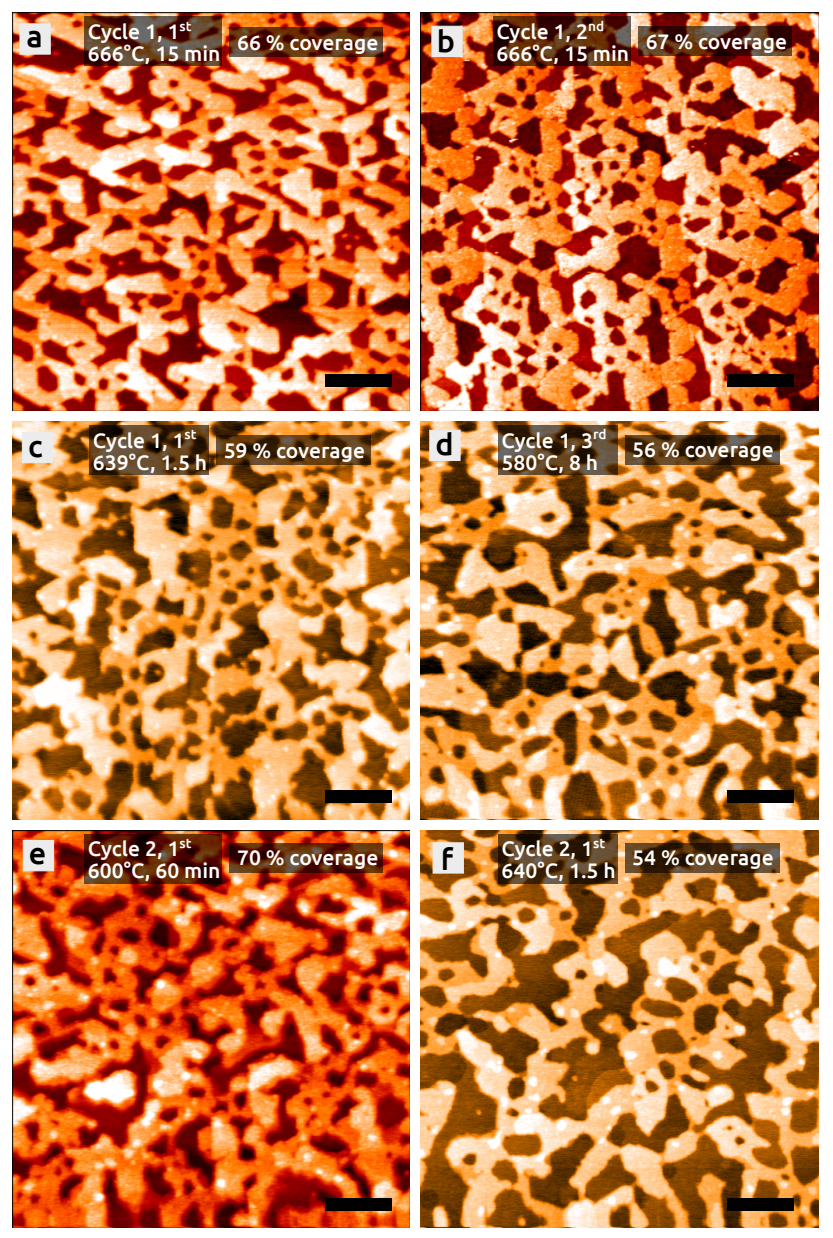

Figure 3: Morphology of the 2.3 ML ultra-thin ceria film during 2 redox cycles. All images show the topography whereas most of them were obtained by nc-AFM, despite one STM image (b). Images in a red colour were obtained after an oxidation step whereas images in a yellow colour were obtained after a reduction step. The annealing in oxygen was done with an oxygen pressure of $p_{\mathrm{O} 2}=5.0 \times 10^{-7}$ mbar. STM parameters: (b) $U_{\text {Bias }}=1.0, I=0.06$, $v=1.0 \mathrm{~Hz}$, nc-AFM parameters: (a) $\triangle f=-11.1 \mathrm{~Hz}, f_{0}=300.0 \mathrm{kHz},(\mathrm{c}) \triangle f=-13.6 \mathrm{~Hz}$, $f_{0}=314.9 \mathrm{kHz},(\mathrm{d}) \triangle f=-10.4 \mathrm{~Hz}, f_{0}=78.1 \mathrm{kHz}$, (e) $\triangle f=-10.1 \mathrm{~Hz}, f_{0}=75.2 \mathrm{kHz}$, (f) $\triangle f=-18.9 \mathrm{~Hz}, f_{0}=75.2 \mathrm{kHz}$, all: $v=0.5 \mathrm{~Hz}$, scale bars: $50 \mathrm{~nm}$. 
the first reduction (Figure 3c), then to $\sim 56 \%$ after the second reduction at $700{ }^{\circ} \mathrm{C}$ (Figure $\mathrm{S} 2$ in the Supporting Information) where it remained at $\sim 56 \%$ after the third reduction (Figure 3d). The decrease of surface coverage is reversible upon oxidation of the ceria ultrathin film: a comparison of Figure $3 \mathrm{~d}$ and e shows that the coverage increased significantly from $\sim 54 \%$ to $\sim 70 \%$ with reoxidation (Figure 3e) whereas it drops again upon a following reduction to $\sim 54 \%$ (Figure $3 \mathrm{f}$ ). Note that all the latter values can vary from site to site on the entire surface of the crystal, and they also depend on the image quality (see Section 4.5 in the Supporting Information). The reported values merely illustrate the trend of the coverage, which is going towards smaller values when reducing the film, and vice-versa.

Overall, even after a very long reduction at high temperatures, the film coverage decreases down to a saturation value of only $\sigma_{\text {rCeria }} \approx 55 \%$ (support: $\sigma_{\text {rCeria_support }} \approx 45 \%$ ), while the oxidized film covers the surface up to a saturation coverage of $\sigma_{\mathrm{CeO} 2} \approx 70 \%$ (support: $\sigma_{\mathrm{CeO} 2 \_s u p p o r t} \approx 30 \%$ ). The decrease and the increase of the surface coverage have to be related to a significantly large loss or gain of ceria film material, which is discussed in the next Sections.

The good long-range crystallinity did not change with the reduction and oxidation cycles, as shown by the LEED image (Figure 4). Around the ceria-related spots six new satellite peaks appeared after reduction (see gray circles in Figure 4d). The distance between the satellite peaks is compatible with a three times smaller periodicity with respect to the ceria surface lattice. A $(3 \times 3)$ periodicity was already observed after the growth of metallic cerium atoms on an ultra-thin ceria film ${ }^{44}$ and by mild temperature heating in an hydrogen partial pressure ${ }^{45}$, and it was ascribed to the $\mathrm{Ce}_{3} \mathrm{O}_{5}$ phase ${ }^{44}$. This reduced phase has a $\mathrm{Ce}^{3+}$ concentration of around $67 \%$, significantly higher than the one measured for the film here. For this reason, in agreement with Ref. 19, we ascribe the LEED pattern observed after reduction to a situation, in which the film has not fully reached the stoichiometry nor the full $(3 \times 3)$ periodicity of the $\mathrm{Ce}_{3} \mathrm{O}_{5}$ phase.

Work function. The analysis of the WF supplies additional information about the 


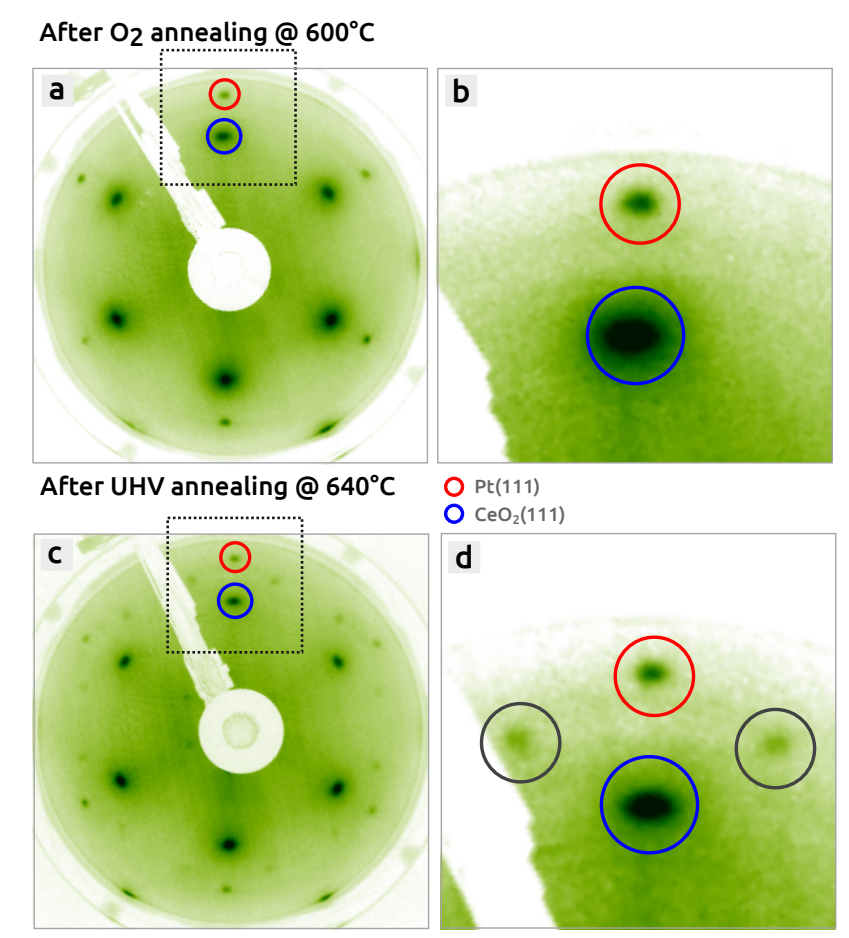

Figure 4: LEED images of the 2.3 ML ultra-thin ceria film after its oxidation (a,b) and following reduction $(\mathrm{c}, \mathrm{d})$ during the second redox cycle. The LEED image (b) and (d) show subtle details with an increased contrast in the region of image (a) and (c), respectively, marked by the dotted gray squares. The LEED images were obtained at an energy of $65 \mathrm{eV}$.

changes of the morphology that appear during a redox step. For this purpose, we conducted KPFM experiments during the second redox cycle on the ultra-thin ceria film and analyzed possible WF changes of the $\mathrm{Pt}(111)$ surface induced by ceria. Figure 5 shows the film after the first oxygen annealing (a,b) and after the following reduction (c-d). The images in Figure 5a and c show the surface topography whereas images (b) and (d) represent the surface WF. A pair of images (e.g., a and b) was recorded in one single KPFM measurement.

Basically three Pt terraces can be found in Figure 5a (label Pt1 to Pt3), which are all separated by integer values of the basic step height of the $\operatorname{Pt}(111)$ surface $\left(h_{\mathrm{Pt}}=a_{\mathrm{Pt}, \mathrm{lit}} / \sqrt{3} \approx\right.$ $2.26 \AA$ ) (see Table $\mathrm{S} 6$ in the Supporting Information). The $\mathrm{CeO}_{2}$ islands have a height of either two or three ML (see Table S7 in the Supporting Information), which can be seen by the gray horizontal lines in the profile of Figure 5a: the distance of two lines equals the single 

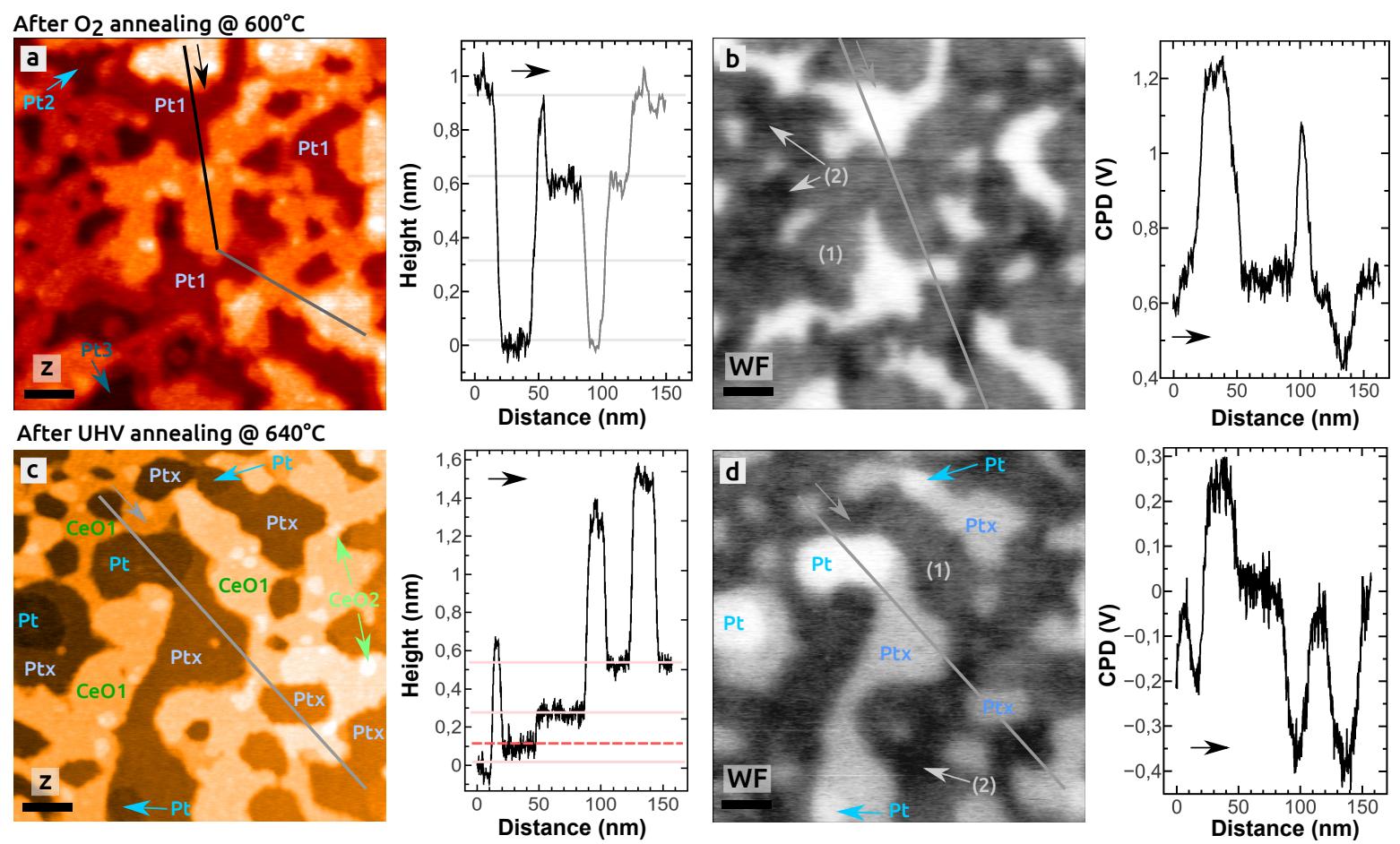

Figure 5: The 2.3 ML ultra-thin ceria film after its oxidation (a,b) and reduction (c-d) during the second redox cycle. The film was oxidized at $600{ }^{\circ} \mathrm{C}$ in $5.0 \times 10^{-7} \mathrm{mbar}_{2}$ during 60 minutes whereas afterwards it was reduced by UHV annealing at $639{ }^{\circ} \mathrm{C}$ during 100 minutes. The images on the top (a,c) show the surface topography $(\mathrm{z})$ and the images at the bottom $(b, d)$ the WF. Images $(a, b)$ were obtained in one single KPFM experiment. The same applies for images (c,d). All labels in the images and profiles (a,c) are explained in the text. KPFM parameters: (a,b) $\triangle f=-14.0 \mathrm{~Hz}(\mathrm{c}, \mathrm{d}) \triangle f=-19.0 \mathrm{~Hz}$, all: $f_{0}=75.2$ $\mathrm{kHz}, f_{\mathrm{ac}}=650 \mathrm{~Hz}, U_{\mathrm{ac}}=500 \mathrm{mV}, v=0.5 \mathrm{~Hz}$, scale bars: $10 \mathrm{~nm}$.

ML height, which is given by $h_{\mathrm{CeO} 2}=a_{\mathrm{CeO} 2 \text {,lit }} / \sqrt{3}=3.12 \pm 0.01 \AA$, with the lattice constant of $\mathrm{CeO}_{2}$ being $a_{\mathrm{CeO} 2 \text {,lit }}=5.41 \pm 0.01 \AA$ (see Table S3 in the Supporting Information). Note that this height can also be assumed for ceria at the interface with $\operatorname{Pt}(111)$ since a quite similar value was recently found by TEM $(3.07 \text { to } 3.10 \AA)^{46}$.

The corresponding WF image (Figure 5b) exhibits strong contrast changes in the range of $\sim 0.8 \mathrm{eV}$ (see profile). A comparison with the topography image (Figure 5a) shows that the uncovered substrate surface has a higher WF (bright regions) than the oxidized film 
(dark gray regions). An analysis of also other KPFM images yields a mean WF difference of around $\triangle \phi_{\mathrm{CeO} 2 / \mathrm{Pt}-\mathrm{Pt}}=\phi_{\mathrm{CeO} 2 / \mathrm{Pt}}-\phi_{\mathrm{Pt}} \approx-0.55 \pm 0.05 \mathrm{eV}$ between ceria on $\mathrm{Pt}(111)$ and the free $\operatorname{Pt}(111)$ support. Note that some regions of the islands decrease the WF even more by $\sim-0.2 \mathrm{eV}$ (e.g., compare region (1) with (2)) so that the WF difference can reach a value of even $\triangle \phi_{\mathrm{CeO} / \mathrm{Pt}-\mathrm{Pt}} \approx-0.75 \pm 0.05 \mathrm{eV}$.

After the reduction of the film (Figure 5c and d), most of the terraces (label Ptx) are separated by an integer value of a single step with a height of $h_{\mathrm{Ptx}} \approx 2.5 \pm 0.3 \AA$ (horizontal light red lines in the profile) - a value that will be discussed in the next section. A major observation is that a few other terraces of the support (label Pt) are not separated by an integer value of $h_{\mathrm{Ptx}}$ from the Ptx terraces: as it can be seen in the exemplifying profile in Figure 5c such terraces (dashed red line) are somewhat in between two Ptx terraces (light red lines). An analysis of the height difference between the Pt and Ptx terraces (see Section 4.4 of the Supporting Information) yields values ranging from $h_{\mathrm{Pt}-\mathrm{Ptx}} \approx 0.7$ to $\sim 1.6 \AA$, which are clearly below the single Pt step height of $h_{\mathrm{Pt}} \approx 2.26 \AA$. An extensive analysis of the height differences between the support and the ceria islands (see Section 4.4 in the Supporting Information) shows that it is very difficult to determine the height of the ceria islands due to the two existing support regions Pt and Ptx. A rough estimation leads to ceria island heights between one and three ML measured from the Pt regions (see Table S8 in the Supporting Information). Note that for the partially reduced ceria film in Figure 5c, we assume a single ML height that is close to the one of $\mathrm{CeO}_{2}\left(h_{\mathrm{CeO} 2}=3.12 \pm 0.01 \AA\right)$.

When comparing the topography image (Figure 5c) with the one of the WF (Figure 5d), a second major observation can be made with respect to the support: at the few terraces labeled by $\mathrm{Pt}$, which make $\sigma_{\mathrm{rCeria}-\mathrm{Pt}}=(5 \pm 4) \%$ of the entire surface, a very high $\mathrm{WF}$ can be seen (bright contrast). In comparison, the WF of the other terraces (label Ptx, gray contrast) is lower by $\triangle \phi_{\mathrm{Ptx}-\mathrm{Pt}}=\phi_{\mathrm{Ptx}}-\phi_{\mathrm{P}}, \approx-0.20 \pm 0.05 \mathrm{eV}$. This automatically means that the chemical composition of the support is different in these two surface regions.

On the reduced ceria film, the WF is decreased with respect to the Ptx terraces (dark gray 
regions), reaching a mean WF difference of $\triangle \phi_{\mathrm{rCeria} / \mathrm{Pt}-\mathrm{Ptx}}=\phi_{\mathrm{rCeria} / \mathrm{Pt}}-\phi_{\mathrm{Ptx}} \approx-0.40 \pm 0.05$ $\mathrm{eV}$. Considering the Pt terraces the difference is even larger: it is around $\Delta \phi_{\mathrm{rCeria} / \mathrm{Pt}-\mathrm{Pt}} \approx$ $-0.60 \pm 0.05 \mathrm{eV}$. Note that there are some small regions of the film, which decrease the WF even more by $\sim-0.1 \mathrm{eV}$ (e.g., compare region (1) with (2) in Figure 5d).

\section{DISCUSSION}

The uncovered Pt support. Some interesting aspects observed during the reduction/oxidation of the Pt supported ceria film require further discussion. The reversible decrease of the oxide film coverage upon reduction is ascribed to a reversible loss of cerium oxide during the vacuum thermal cycle, since no evident increase of the average ceria height was observed.

Before any detailed interpretation of the observed behaviour of the ceria films with reducing and oxidizing treatment is given, the chemical composition of the different phases observed on the support of the reduced ceria film has to be clarified. This is also needed in view of the determination of absolute WF values, which is particularly useful for a clear understanding of ceria's WF reduction. In the following, we therefore focus first on the reduced ceria film in Figure 5c and d.

It is clear that the chemical composition of the two regions, Pt and Ptx, must be different and that only oxygen or cerium in the ceria film can play a role in a possible change of the $\mathrm{Pt}$ (111) composition. With respect to oxygen, the surface WF generally increases when oxygen is dissociatively adsorbed on the $\mathrm{Pt}(111)$ surface, as experimentally observed by the classical Kelvin probe technique (WF changes of up to $\Delta \phi=+0.3 \mathrm{eV})^{47}$ and ultraviolet photoemission spectroscopy (WF change of $\triangle \phi=+0.54 \mathrm{eV}$ for $0.75 \mathrm{ML}$ of $\mathrm{O}$ ) ${ }^{48}$, and as calculated by density functional theory (DFT) $(\triangle \phi=+0.8 \mathrm{eV} \text { for } 1 \mathrm{ML} \text { of } \mathrm{O})^{49}$. This leads then to the hypothesis that oxygen is adsorbed in the Pt regions whereas the Ptx regions are made from clean $\mathrm{Pt}(111)$. However, it is unlikely that atomic oxygen is adsorbed in well-confined tiny regions only, which make $5 \%$ of the surface, while a rather uniform 
distribution of oxygen on the entire, uncovered support is expected. Furthermore, in the conditions used for the present study, a possible adsorption or oxidation of the $\operatorname{Pt}(111)$ surface is also very unlikely: temperature programmed desorption (TPD) experiments show a 'last peak' of oxygen desorption at $477^{\circ} \mathrm{C}^{50}$ and $577^{\circ} \mathrm{C}^{51}$. Furthermore, photoemission $\mathrm{XPS}^{52}$ and X-ray diffraction/reflectivity measurements ${ }^{53}$ after a high pressure exposure of oxygen on $\mathrm{Pt}(111)$ show almost no oxygen after a vacuum post-annealing at $690{ }^{\circ} \mathrm{C}$ and 447 ${ }^{\circ} \mathrm{C}$, respectively. In comparison to all the latter literature results, a temperature of $640{ }^{\circ} \mathrm{C}$ and relatively long annealing times of hours were used for the reduction experiments in this work. We therefore believe that the Pt and Ptx regions cannot be assigned to atomic oxygen on $\mathrm{Pt}(111)$ and to bare $\mathrm{Pt}(111)$, respectively.

The only candidate that remains is cerium, which we believe is built into the $\operatorname{Pt}(111)$ surface upon a reduction of the ceria film, forming a CePt alloy even at $640{ }^{\circ} \mathrm{C}$ as stated in Ref. 54. Depending on the temperature and amount of cerium, the CePt alloy forms several new atomic structures that could be all atomically resolved in several STM works and revealed by LEED ${ }^{25-27,54-56}$. Unfortunately, we did not obtain any high resolution to prove its existence, probably due to the temperature of $640{ }^{\circ} \mathrm{C}^{26}$ that was slightly too low for the creation of the otherwise highly ordered alloy structures that were observed at 730 ${ }^{\circ} \mathrm{C}$ in Ref. ${ }^{26}$.

If cerium forms an alloy with platinum, the surface WF certainly changes due to a different electronic structure with respect to pure Pt(111). And indeed, a DFT calculation shows that for several surface configurations of $\mathrm{CePt}_{5}$, which is the most stable structure for the alloy in general, the WF is at least as high as the WF of $\mathrm{Pt}(111)$, if not smaller ${ }^{57}$ (note that the WF of cerium is $\phi_{\text {Ce,poly }}=2.9 \mathrm{eV}^{58}$ ). The most stable surface configuration is fomed by layers of $\mathrm{Pt}_{4} / \mathrm{CePt}_{2} / \mathrm{Pt}_{3}$ on $\mathrm{Pt}(111)$ (see Figure S6b in the Supporting Information) and has a WF that is by $\triangle \phi_{\mathrm{CePt} 5 / \operatorname{Pt}(111)-\operatorname{Pt}(111)}=-0.25 \mathrm{eV}$ lower than the one of $\operatorname{Pt}(111)^{57}$, which perfectly agrees with our experimental value of $\triangle \phi_{\mathrm{Ptx}-\mathrm{Pt}} \approx-0.20 \pm 0.05 \mathrm{eV}$.

If the latter predicted WF reduction is considered, we may do the following assumption: 
the regions of the support with a high WF (label Pt) in Figure 5c and d can be assigned to pure $\operatorname{Pt}(111)(\mathrm{Pt} \equiv \operatorname{Pt}(111))$. The other regions with a $\triangle \phi_{\mathrm{Pt}-\mathrm{Ptx}} \approx-0.20 \pm 0.05 \mathrm{eV}$ lower WF (label Ptx) are then regions covered by the alloy, which we assume to be $\mathrm{CePt}_{5}$ for simplicity. If so, one interesting observation can be made concerning the coverage: in the following, we only consider the values of the second redox cycle. After the reduction of the ceria film, the uncovered $\operatorname{Pt}(111)$ makes only $\sigma_{\text {rCeria_Pt }} \approx 5 \%$ of the entire surface area, which is much smaller than the surface area of the uncovered $\operatorname{Pt}(111)$ support when the film is in its oxidized form $\left(\sigma_{\mathrm{CeO} 2 \_ \text {Support }} \approx 30 \%\right)$. From this it follows that during the reduction of an oxidized ceria film, large parts of the uncovered $\mathrm{Pt}(111)$ support are supplied with cerium atoms to form the alloy. This can only happen by a lateral transport of cerium atoms released from the shrinking ceria film to regions of the uncovered $\operatorname{Pt}(111)$ support.

The question now is if the amount of released cerium atoms is compatible with the fraction of surface covered by the $\mathrm{CePt}_{5}$ alloy $\left(\sigma_{\text {rCeria_alloy }}=\sigma_{\text {rCeria_support }}-\sigma_{\text {rCeria_Pt }} \approx 41 \%\right)$. As shown in detail in the Supporting Information (see Section 4.6, Model 1), the amount of cerium atoms released during the reduction process is enough to cover a surface fraction of $\sigma_{\text {rCeria_alloy,calc }} \approx 63 \%$ by a one monolayer thick $\mathrm{CePt}_{5}$ alloy. This value is significantly larger than the experimental one $\left(\sigma_{\text {rCeria_alloy }} \approx 41 \%\right.$ or even $\left.\sigma_{\text {rCeria_support }}=46 \%\right)$, suggesting that part of the cerium might be involved in the formation of an alloy that is more than one monolayer thick or richer in cerium in some regions ${ }^{59}$. However, because the surface coverage of the reduced ceria film remains constant even after a very long annealing time at high temperatures, there must be a balance between the decrease of the ceria film coverage and the formation of the alloy. In other words, a mechanism must stop the decomposition of the ceria film. In a second model (see Section 4.6 in the Supporting Information, Model 2) we hypothesize that the $\mathrm{CePt}_{5}$ alloy is only one monolayer thick, and that the reduced ceria film and the alloy cover the entire surface. With these assumptions, we obtain a value of around $\sigma_{\text {rCeria_alloy,calc }} \approx 40 \%$, which is very close to the experimental value $\left(\sigma_{\text {rCeria_alloy }} \approx 41 \%\right.$ or even $\sigma_{\text {rCeria_support }}=46 \%$ ). This confirms the initial hypothesis that the gray regions in the 
WF image (Ptx regions in Figure 5d) are covered by a surface alloy with a composition close to $\mathrm{CePt}_{5}$ and with a thickness close to one monolayer.

For a Pt-Ce alloy like $\mathrm{CePt}_{5}$, it is expected that the first atomic interlayer distances at the surface are different with respect to the interlayer distances of pure $\operatorname{Pt}(111)^{57}$. Although steps are not discussed in the latter and other work, differences in the interlayer distances can principally explain our observation of the small step heights $h_{\mathrm{Pt}-\mathrm{Ptx}}$, when passing from a Pt to a Ptx region (Figure 5c). Note that such small steps were also observed between $\mathrm{Pt}(111)$ and a Pt-Ce alloy by $\mathrm{STM}^{26,54}$. However, it remains unclear why the Ptx terraces are separated by an integer value of $h_{\mathrm{Ptx}} \approx 2.5 \pm 0.3 \AA$, which is $\sim 0.3 \AA$ larger than the single step height of $\operatorname{Pt}(111)\left(h_{\mathrm{Pt}} \approx 2.26 \AA\right)$ : if all Ptx terraces are formed by one and the same type of single layer alloy they should be separated by an integer value of $h_{\mathrm{Pt}}$. The single step heights measured for Pt and Ptx actually agree within the error, so that it can be assumed that both values represent indeed the single step height of $\operatorname{Pt}(111)$. However, if this is not the case we speculate that the density of cerium may slightly differ on the Ptx terraces, which might explain the higher step height $h_{\mathrm{Ptx}}$.

Concluding this Section, we propose the following mechanism for a redox cycle of ceria on $\mathrm{Pt}(111)$ : upon reduction of ceria, the ceria film looses oxygen, which leaves the sample in form of $\mathrm{O}_{2}$, but also cerium, which goes onto the uncovered $\mathrm{Pt}(111)$ support forming a one monolayer $\mathrm{CePt}_{5}$-like alloy. The latter reduces the $\mathrm{WF}$ by $\triangle \phi_{\mathrm{CePt} 5 / \operatorname{Pt}(111)-\operatorname{Pt}(111)} \approx$ $-0.20 \pm 0.05 \mathrm{eV}$. In turn, when the reduced film is oxidized, all the cerium in $\mathrm{CePt}_{5} / \mathrm{Pt}(111)$ is consumed to form new ceria, as also shown by other experiments ${ }^{25-27,54}$. Therefore the Pt(111) support serves as a reservoir for cerium atoms during a reduction of ceria. The $\mathrm{Pt}(111)$ support then releases the cerium atoms upon oxidation such that new ceria is formed.

WF reduction by ceria. Thanks to the identification of the support in the case of the reduced ceria film, we can now focus on the WF reduction of the ceria film. If we consider the reduced ceria film, we find a mean WF reduction of $\triangle \phi_{\mathrm{rCeria} / \mathrm{Pt}-\mathrm{Pt}} \approx-0.60 \pm 0.05 \mathrm{eV}$ of the Pt(111) surface by the ceria film. Interestingly, for the oxidized film we find a slightly smaller 
mean WF reduction of $\triangle \phi_{\mathrm{CeO} 2 / \mathrm{Pt}-\mathrm{Pt}} \approx-0.55 \pm 0.05 \mathrm{eV}$ between $\mathrm{CeO}_{2}$ on $\mathrm{Pt}(111)$ and the pure $\mathrm{Pt}(111)$ support. Note that the work function difference of $\Delta \phi_{\mathrm{CeO} 2 / \mathrm{Pt}-\mathrm{Pt}}-\triangle \phi_{\mathrm{rCeria} / \mathrm{Pt}-\mathrm{Pt}}=$ $\triangle \phi_{\mathrm{CeO} / \mathrm{Pt} \text { - } \mathrm{rCeria} / \mathrm{Pt}} \approx 50 \mathrm{meV}$ between oxidized and reduced ceria was also observed on $\mathrm{CeO}_{2}$ nanoparticles reduced by $\mathrm{CO}$ exposure ${ }^{60}$. Furthermore, on the oxidized as well as on the reduced ceria film, small ceria regions further decrease the WF by up to $\sim-0.2 \mathrm{eV}$.

So far, we have no clear explanation for the relatively strong WF reduction of the $\mathrm{Pt}(111)$ surface by the ceria film. We can only state that the ceria film follows the general trend of ultra-thin oxide films to modify the WF of the metal surface ${ }^{61}$ : for instance, it has been shown that $\mathrm{MgO}$ ultra-thin films strongly reduce the WF of metal supports by more than $1 \mathrm{eV}^{61-63}$, as indeed experimentally verified on $\mathrm{MgO} / \mathrm{Ag}(001)^{64,65}$. In general, the basic mechanism behind is a net dipole formed at the film-support interface, which is a result of either a compressive electrostatic effect or of a net charge transfer between the film and the metal support ${ }^{61}$. Both mechanims strongly depend on the nature of the metal support, and they can appear at the same time whereas their interplay quite often determines the resulting sign of the WF change ${ }^{61}$.

A charge transfer at individual $\mathrm{Ce}, \mathrm{O}$ and $\mathrm{Pt}$ atoms can be positive or negative ${ }^{66,67}$, and a net charge transfer from $\mathrm{Pt}$ to the film is expected for ceria ultra-thin films on $\mathrm{Pt}(111)^{46,67}$. This is similar to the situation of ceria films on other metal surfaces with a low WF like $\mathrm{Cu}(111), \mathrm{Ag}(111)$ and $\mathrm{Au}(111)$ where also a net charge transfer from the metal to the film is expected, which by itself would imply a positive WF change. Compressive electrostatic effects or surface relaxations may compensate the charge transfer induced dipole and explain the observed WF reduction, altough this possibility remains simply speculative. Unknown remains also the further WF decrease of some small ceria regions, which we speculate to be possibly ascribed to differences in the atomic structure. Overall, to shed more light onto ceria's WF reduction on Pt(111) an extensive and complete WF analysis by denisty functional theory (DFT) has to be accomplished in future. 


\section{CONCLUSIONS}

With the help of LEED, STM, nc-AFM, KPFM and XPS we have shown that the morphology and crystallinity of UHV prepared ultra-thin cerium oxide (ceria) films on $\operatorname{Pt}(111)$ do not change when they are exposed to the ambient air and cleaned from surface contaminations by annealing in molecular oxygen at a temperature of $650{ }^{\circ} \mathrm{C}$. In view of a recent work accomplished on thick ceria films ${ }^{23}$, we can conclude that any ceria sample can be transported in air and cleaned afterwards in oxygen, without significant modifications in structure, morphology and stoichimetry.

With the help of STM and nc-AFM experiments, we show that in a redox cycle the ceria film shrinks (expands) upon a reduction (oxidation) step, without loosing its crystallinity as verified by LEED. Thanks to the latter experiments and KPFM, we can assume that cerium atoms are incorporated into the $\mathrm{Pt}(111)$ forming an alloy during reduction, which changes the WF of the support as observed by KPFM $\left(\triangle \phi_{\mathrm{CeP} t_{5} / \operatorname{Pt}(111)-\operatorname{Pt}(111)} \approx-0.20 \pm 0.05 \mathrm{eV}\right)$. Our model explains such redox phenomena by considering the role of the $\operatorname{Pt}(111)$ support: it serves as a reservoir for cerium (reduction), which can form new ceria on $\operatorname{Pt}(111)$ during an oxidation step.

Surprisingly, our KPFM experiments show that the WF of the Pt(111) support is reduced by a clean ultra-thin ceria film, independently on the oxidation state of the film. Oxidized ceria in the form of $\mathrm{CeO}_{2}(111)$ reduces the $\mathrm{Pt}(111) \mathrm{WF}$ by $\triangle \phi_{\mathrm{CeO} 2 / \mathrm{Pt}-\mathrm{Pt}} \approx-0.55 \pm 0.05 \mathrm{eV}$, whereas reduced ceria lowers it by $\triangle \phi_{\text {rCeria } / \mathrm{Pt}-\mathrm{Pt}} \approx-0.60 \pm 0.05 \mathrm{eV}$.

\section{ACKNOWLEDGMENT}

Support from the COST Action CM1104 is gratefully acknowledged. C. B. highly acknowledges the support from the Agence Nationale de la Recherche through project REACTIVITY (ANR-17-CE09-0045) and project CHAMAN (ANR-17-CE24-0011). 


\section{SUPPORTING INFORMATION DESCRIPTION}

\section{Supporting Information}

The Supporting Information is available free of charge on the ACS Publications website at DOI: ... . Details about the sample preparation, UHV techniques (SPM, LEED and XPS), image analysis and supporting experiments (PDF).

\section{Author information}

\section{Corresponding author}

E-mail: barth@cinam.univ-mrs.fr

\section{ORCID}

Paola Luches: 0000-0003-1310-5357

Clemens Barth: 0000-0003-4250-4533

\section{Author contributions}

G. G. and C. B. conducted the experimental work. G. G., P. L. and C. B. accomplished the image analysis, data interpretation and conclusions. P. L. and C. B. wrote the manuscript. Notes

The authors declare no competing financial interests.

\section{References}

(1) Montini, T.; Melchionna, M.; Monai, M.; Fornasiero, P. Fundamentals and Catalytic Applications of $\mathrm{CeO}_{2}$-Based Materials. Chem. Rev. 2016, 116, 5987-6041.

(2) Devaiah, D.; Reddy, L. H.; Park, S.-E.; Reddy, B. M. Ceria-Zirconia Mixed Oxides: Synthetic Methods and Applications. Catal. Rev. 2018, 60, 177-277.

(3) Paier, J.; Penschke, Ch.; Sauer, J. Oxygen Defects and Surface Chemistry of Ceria: Quantum Chemical Studies Compared to Experiment. Chem. Rev. 2013, 113, 3949-85. 
(4) Ratnasamy, C.; Wagner, J. P. Water Gas Shift Catalysis. Catal. Rev. 2009, 51, 325-440.

(5) Gorte, R. J. Ceria in catalysis: From Automotive Applications to the Water-Gas Shift Reaction. AIChE J. 2010, 56, 1126-1135.

(6) Fan, L.; Wang, C.; Chen, M.; Zhu, B. Recent Development of Ceria-Based (Nano)Composite Materials for Low Temperature Ceramic Fuel Cells and ElectrolyteFree Fuel Cells. J. Power Sources 2013, 234, 154-174.

(7) Shaikh, S. P. S.; Muchtar, A.; Somalu, M. R. A Review on the Selection of Anode Materials for Solid-Oxide Fuel Cells. Renew. Sustain. Energy Rev. 2015, 51, 1-8.

(8) Fiala, R.; Figueroba, A.; Bruix, A.; Vaclavu, M.; Rednyk, A.; Khalakhan, I.; Vorokhta, M.; Lavkova, J.; Illas, F.; Potin, V. et al. High Efficiency of $\mathrm{Pt}^{2+}-\mathrm{CeO}_{2}$ Novel Thin Film Catalyst as Anode for Proton Exchange Membrane Fuel Cells. Appl. Catal. B Environ. 2016, 197, 262-270.

(9) Matsumoto, S. Recent Advances in Automobile Exhaust Catalysts. Catal. Today 2004, 90, 183-190.

(10) Ganduglia-Pirovano, M. V. The Non-Innocent Role of Cerium Oxide in Heterogeneous Catalysis: A Theoretical Perspective. Catal. Today 2015, 253, 20-32.

(11) Niu, G.; Zoellner, M. H.; Schroeder, T.; Schaefer, A.; Jhang, J.-H.; Zielasek, V.; Bäumer, M.; Wilkens, H.; Wollschläger, J.; Olbrich, R. et al. Controlling the Physics and Chemistry of Binary and Ternary Praseodymium and Cerium Oxide Systems. Phys. Chem. Chem. Phys. 2015, 17, 24513-24540.

(12) Freund, H. J. Model Studies in Heterogeneous Catalysis. Chem. Eur. J. 2010, 16, 9384-9397.

(13) Luches, P.; Valeri, S. Structure, Morphology and Reducibility of Epitaxial Cerium Oxide Ultrathin Films and Nanostructures. Materials (Basel). 2015, 8, 5818-5833. 
(14) Mullins, D. R. The Surface Chemistry of Cerium Oxide. Surf. Sci. Rep. 2015, 70, $42-85$.

(15) Rodriguez, J. A.; Grinter, D. C.; Liu, Z.; Palomino, R. M.; Senanayake, S. D. CeriaBased Model Catalysts: Fundamental Studies on the Importance of the Metal-Ceria Interface in $\mathrm{CO}$ Oxidation, the Water-Gas Shift, $\mathrm{CO}_{2}$ Hydrogenation, and Methane and Alcohol Reforming. Chem. Soc. Rev. 2017, 46, 1824-1841.

(16) Lu, J.-L.; Gao, H.-J.; Shaikhutdinov, S.; Freund, H.-J. Morphology and Defect Structure of the $\mathrm{CeO}_{2}(111)$ Films Grown on $\mathrm{Ru}(0001)$ as Studied by Scanning Tunneling Microscopy. Surf. Sci. 2006, 600, 5004-5010.

(17) Lauritsen, J. V.; Reichling, M. Atomic Resolution Non-Contact Atomic Force Microscopy of Clean Metal Oxide Surfaces. J. Phys. Condens. Matter 2010, 22, 263001.

(18) Castellarin-Cudia, C.; Surnev, S.; Schneider, G.; Podlucky, R.; Ramsey, M. G.; Netzer, F. P. Strain-Induced Formation of Arrays of Catalytically Active Sites at the MetalOxide Interface. Surf. Sci. 2004, 554, L120-L126.

(19) Luches, P.; Pagliuca, F.; Valeri, S. Structural and Morphological Modifications of Thermally Reduced Cerium Oxide Ultrathin Epitaxial Films on Pt(111). Phys. Chem. Chem. Phys. 2014, 16, 18848-18857.

(20) Olbrich, R.; Murgida, G.; Ferrari, V.; Barth, C.; Llois, A. M.; Reichling, M.; GandugliaPirovano, M. V. Surface Stabilises Ceria in Unexpected Stoichiometry. J. Phys. Chem. C 2017, 121, 6844-6851.

(21) Höcker, J.; Krisponeit, J.-O.; Schmidt, Th.; Falta, J.; Flege, J. I. The Cubic-ToHexagonal Phase Transition of Cerium Oxide Particles: Dynamics and Structure. Nanoscale 2017, 9, 9352-9358. 
(22) Wilkens, H.; Schuckmann, O.; Oelke, R.; Gevers, S.; Reichling, M.; Schaefer, A.; Bäumer, M.; Zoellner, M. H.; Niu, G.; Schroeder, T. et al. Structural Transitions of Epitaxial Ceria Films on Si(111). Phys. Chem. Chem. Phys. 2013, 15, 18589-18599.

(23) Barth, C.; Laffon, C.; Olbrich, R.; Ranguis, A.; Parent, Ph.; Reichling, M. A Perfectly Stoichiometric and Flat $\mathrm{CeO}_{2}(111)$ Surface on a Bulk-Like Ceria Film. Sci. Rep. 2016, 6, 21165 .

(24) Gasperi, G.; Amidani, L.; Benedetti, F.; Boscherini, F.; Glatzel, P.; Valeri, S.; Luches, P. Electronic Properties of Epitaxial Cerium Oxide Films During Controlled Reduction and Oxidation Studied by Resonant Inelastic X-ray Scattering. Phys. Chem. Chem. Phys. 2016, 18, 20511-20517.

(25) Schierbaum, K.-D. Ordered Ultra-Thin Cerium Oxide Overlayers on Pt(111) Single Crystal Surfaces Studied by LEED and XPS. Surf. Sci. 1998, 399, 29-38.

(26) Berner, U.; Schierbaum, K. Cerium Oxide Layers on Pt(111): a Scanning Tunneling Microscopy Study. Thin Solid Films 2001, 400, 46-49.

(27) Grinter, D. C.; Ithnin, R.; Pang, C. L.; Thornton, G. Defect Structure of Ultrathin Ceria Films on Pt(111): Atomic Views from Scanning Tunnelling Microscopy. J. Phys. Chem. C 2010, 114, 17036-17041.

(28) Zhao, X.; Ma, S.; Hrbek, J.; Rodriguez, J. A. Reaction of Water with Ce-Au(111) and $\mathrm{CeO}_{x} / \mathrm{Au}(111)$ Surfaces: Photoemission and STM Studies. Surf. Sci. 2007, 601, 2445-2452.

(29) Hasegawa, T.; Shahed, S. M. F.; Sainoo, Y.; Beniya, A.; Isomura, N.; Watanabe, Y.; Komeda, T. Epitaxial Growth of $\mathrm{CeO}_{2}(111)$ Film on $\mathrm{Ru}(0001)$ : Scanning Tunneling Microscopy (STM) and X-Ray Photoemission Spectroscopy (XPS) Study. J. Chem. Phys. 2014, 140, 044711. 
(30) Barth, C.; Claeys, C.; Henry, C. R. Surface Preparation of Hard Ionic Crystals by Ultrahigh Vacuum Cleavage. Rev. Sci. Instr. 2005, 76, 083907.

(31) Reichling, M.; Huisinga, M.; Gogoll, S.; Barth, C. Degradation of the $\mathrm{CaF}_{2}(111)$ Surface by Air Exposure. Surf. Sci. 1999, 439, 181-190.

(32) Berner, U.; Schierbaum, K.; Jones, G.; Wincott, P.; Haq, S.; Thornton, G. Ultrathin Ordered $\mathrm{CeO}_{2}$ Overlayers on $\mathrm{Pt}(111)$ : Interaction with $\mathrm{NO}_{2}, \mathrm{NO}, \mathrm{H}_{2} \mathrm{O}$ and CO. Surf. Sci. 2000, 467, 201-213.

(33) Wilson, E. L.; Grau-Crespo, R.; Pang, C. L.; Cabailh, G.; Chen, Q.; Purton, J. A.; Catlow, C. R. A.; Brown, W. A.; de Leeuw, N. H.; Thornton, G. Redox Behavior of the Model Catalyst $\mathrm{Pd} / \mathrm{CeO}_{2-\mathrm{x}} / \mathrm{Pt}(111)$. J. Phys. Chem. C 2008, 112, 10918-10922.

(34) Matharu, J.; Cabailh, G.; Lindsay, R.; Pang, C. L.; Grinter, D. C.; Skála, T.; Thornton, G. Reduction of Thin-Film Ceria on Pt(111) by Supported Pd Nanoparticles Probed with Resonant Photoemission. Surf. Sci. 2011, 605, 1062-1066.

(35) Luches, P.; Pagliuca, F.; Valeri, S. Morphology, Stoichiometry, and Interface Structure of $\mathrm{CeO}_{2}$ Ultrathin Films on $\mathrm{Pt}(111)$. J. Phys. Chem. C 2011, 115, 10718-10726.

(36) Luches, P.; Pagliuca, F.; Valeri, S.; Boscherini, F. Structure of Ultrathin $\mathrm{CeO}_{2}$ Films on Pt(111) by Polarization-Dependent X-ray Absorption Fine Structure. J. Phys. Chem. C 2013, 117, 1030-1036.

(37) Barth, C.; Foster, A. S.; Henry, C. R.; Shluger, A. L. Recent Trends in Surface Characterization and Chemistry with High-Resolution Scanning Force Methods. Adv. Mater. 2011, 23, 477-501.

(38) Heiz, U.; Landman, U. Nanocatalysis; Springer Verlag; Berlin, 2007.

(39) Freund, H. J.; Pacchioni, G. Oxide Ultra-Thin Films on Metals: New Materials for the Design of Supported Metal Catalysts. Chem. Soc. Rev. 2008, 37, 2224-2242. 
(40) Mullins, D. R.; Overbury, S. H.; Huntley, D. R. Electron Spectroscopy of Single Crystal and Polycrystalline Cerium Oxide Surfaces. Surf. Sci. 1998, 409, 307-319.

(41) Kundakovic, L.; Mullins, D. R.; Overbury, S. H. Adsorption and Reaction of $\mathrm{H}_{2} \mathrm{O}$ and $\mathrm{CO}$ on Oxidized and Reduced $\mathrm{Rh} / \mathrm{CeO}_{x}(111)$ Surfaces. Surf. Sci. 2000, 457, 51-62.

(42) Henderson, M. A.; Perkins, C. L.; Engelhard, M. H.; Thevuthasan, S.; Peden, C. H. F. Redox Properties of Water on the Oxidized and Reduced Surfaces of $\mathrm{CeO}_{2}(111)$. Surf. Sci. 2003, 526, 1-18.

(43) Flege, J. I.; Kaemena, B.; Höcker, J.; Bertram, F.; Wollschläger, J.; Schmidt, T.; Falta, J. Ultrathin, Epitaxial Cerium Dioxide on Silicon. Appl. Phys. Lett. 2014, 104, 131604.

(44) Duchon, T.; Dvorak, F.; Aulická, M.; Stetsovych, V.; Vorokhta, M.; Mazur, D.; Veltruská, K.; Skala, T.; Myslivecek, J.; Matolínová, I. et al. Ordered Phases of Reduced Ceria as Epitaxial Films on $\mathrm{Cu}(111)$. J. Phys. Chem. C 2013, 118, 357-365.

(45) Höcker, J.; Mentes, T. O.; Sala, A.; Locatelli, A.; Schmidt, T.; Falta, J.; Senanayake, S. D.; Flege, J. I. Unraveling the Dynamic Nanoscale Reducibility $\left(\mathrm{Ce}^{4+} \rightarrow \mathrm{Ce}^{3+}\right)$ of $\mathrm{CeO}_{\mathrm{x}}-\mathrm{Ru}$ in Hydrogen Activation. Adv. Mater. Interfaces 2015, 2, 1500314.

(46) Luches, P.; Giordano, L.; Grillo, V.; Gazzadi, G. C.; Prada, S.; Campanini, M.; Bertoni, G.; Magen, C.; Pagliuca, F.; Pacchioni, G. et al. Atomic Scale Structure and Reduction of Cerium Oxide at the Interface with Platinum. Adv. Mater. Interfaces 2015, 2, 1500375.

(47) Derry, G. N.; Ross, P. N. A. Work Function Change Study of Oxygen Adsorption on $\operatorname{Pt}(111)$ and $\operatorname{Pt}(100)$. J. Chem. Phys. 1985, 82, 2772-2778.

(48) Parker, D. H.; Bartram, M. E.; Koel, B. E. Study of High Coverages of Atomic Oxygen on the Pt(111) Surface. Surf. Sci. 1989, 217, 489-510.

(49) Pang, Q.; Zhang, Y.; Zhang, J.; Xu, K. Structural and Electronic Properties of Atomic 
Oxygen Adsorption on Pt(111): A Density-Functional Theory Study. Appl. Surf. Sci. 2011, 257, 3047-3054.

(50) Weaver, J. F.; Chen, J.-J.; Gerrard, A. L. Oxidation of Pt(111) by Gas-Phase Oxygen Atoms. Surf. Sci. 2005, 592, 83-103.

(51) Devarajan, S. P.; Hinojosa, J. A.; Weaver, J. F. STM Study of High-Coverage Structures of Atomic Oxygen on Pt(111): $\mathrm{p}(2 \times 1)$ and Pt Oxide Chain Structures. Surf. Sci. 2008, 602, 3116-3124.

(52) van Spronsen, M. A.; Frenken, J. W. M.; Groot, I. M. N. Observing the Oxidation of Platinum. Nat. Commun. 2017, 8, 429.

(53) Ellinger, C.; Stierle, A.; Robinson, I. K.; Nefedov, A.; Dosch, H. Atmospheric Pressure Oxidation of $\mathrm{Pt}(111)$. J. Phys. Condens. Matter 2008, 20, 184013.

(54) Berner, U.; Schierbaum, K.-D. Cerium Oxides and Cerium-Platinum Surface Alloys on Pt(111) Single-Crystal Surfaces Studied by Scanning Tunneling Microscopy. Phys. Rev. B 2002, 65, 235404 .

(55) Baddeley, Ch. J.; Stephenson, A. W.; Hardacre, Ch.; Tikhov, M.; Lambert, R. M. Structural and Electronic Properties of Ce Overlayers and Low-Dimensional Pt-Ce Alloys on Pt(111). Phys. Rev. B 1997, 56, 12589-12598.

(56) Kemmer, J.; Praetorius, C.; Krönlein, A.; Hsu, P.-J.; Fauth, K.; Bode, M. Structural Analysis of the Intermetallic Surface Compound $\mathrm{CePt}_{5} / \mathrm{Pt}(111)$. Phys. Rev. B 2014, 90, 195401.

(57) Tereshchuk, P.; Piotrowski, M. J.; Da Silva, J. L. F. Atomic Structure of the La/Pt(111) and $\mathrm{Ce} / \mathrm{Pt}(111)$ Surfaces Revealed by DFT+U Calculations. RSC Adv. 2015, 5, 521528. 
(58) Michaelson, H. B. The Work Function of the Elements and its Periodicity. J. Appl. Phys. 1977, 48, 4729-4733.

(59) Praetorius, C.; Zinner, M.; Held, G.; Fauth, K. Surface Termination of CePt t $_{5} / \mathrm{Pt}(111)$ : The Key to Chemical Inertness. Phys. Rev. B 2015, 92, 195427.

(60) Tanvir, N. B.; Laubender, E.; Yurchenko, O. ; Urban, G. Room Temperature CO Sensing with Metal Oxide Nanoparticles Using Work Function Readout. Procedia Eng. 2016, 168, 284-288.

(61) Prada, S.; Martinez, U.; Pacchioni, G. Work Function Changes Induced by Deposition of Ultrathin Dielectric Films on Metals: A Theoretical Analysis. Phys. Rev. B 2008, 78, 235423.

(62) Butti, G.; Trioni, M. I.; Ishida, H. Electronic Properties Calculation of MgO Thin Films Adsorbed on Semi-Infinite Ag(001). Phys. Rev. B 2004, 70, 195425.

(63) Ling, S.; Watkins, M. B.; Shluger, A. L. Effects of Oxide Roughness at Metal Oxide Interface: $\mathrm{MgO}$ on $\mathrm{Ag}(001)$. J. Phys. Chem. C 2013, 117, 5075-5083.

(64) Bieletzki, M.; Hynninen, T.; Soini, T. M.; Pivetta, M.; Henry, C. R.; Foster, A. S.; Esch, F.; Barth, C.; Heiz, U. Topography and Work Function Measurements of Thin $\mathrm{MgO}(001)$ Films on $\mathrm{Ag}(001)$ by nc-AFM and KPFM. Phys. Chem. Chem. Phys. 2010, 12, 3203-3209.

(65) Mechehoud, F.; Barth, C. Morphology, Work Function, and Silver Ad-Structures of High-Temperature Grown Ultrathin MgO Films on $\mathrm{Ag}(001)$. J. Phys. Chem. C 2015, 119, 23990-23995.

(66) Spiel, C.; Blaha, P.; Suchorski, Y.; Schwarz, K.; Rupprechter, G. $\mathrm{CeO}_{2} / \mathrm{Pt}(111)$ Interface Studied Using First-Principles Density Functional Theory Calculations. Phys. Rev. B 2011, 84, 045412 . 
(67) Graciani, J.; Vidal, A. B.; Rodriguez, J. A.; Sanz, J. F. Unraveling the Nature of the Oxide-Metal Interaction in Ceria-Based Noble Metal Inverse Catalysts. J. Phys. Chem. C 2014, 118, 26931-26938. 


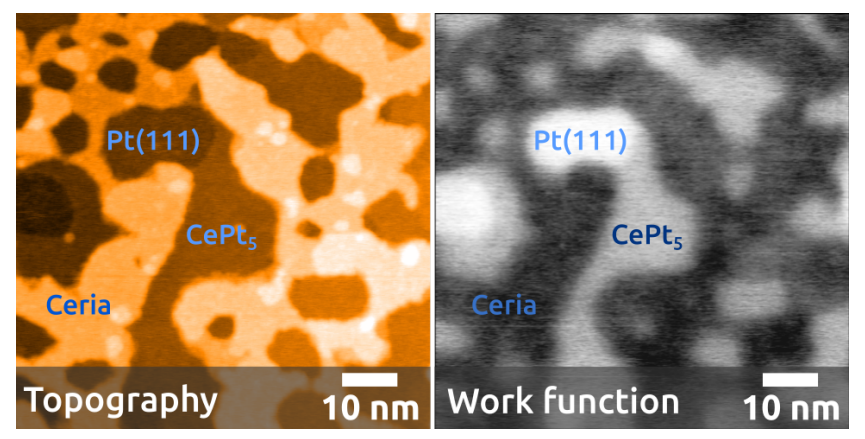

\section{TOC IMAGE}

